\title{
About copper valence and superconductivity
}

\author{
$X$ OUDET and G T BHANDAGE \\ Laboratoire de Magnetisme. CNRS, 1, Place A. Briand, 92195, Meudon. France \\ * Department of Chemistry, Regional College of Education (NCERT). Mysore, India
}

\begin{abstract}
We describe the copper valence in superconductors based on our arguments on $\mathrm{La}_{2} \mathrm{O}_{3}$ crystal structure. In order to explain the two oxygen sites in $\mathrm{La}_{2} \mathrm{O}_{3}$, it has been supposed that $\mathrm{O}_{11}^{1-}$ ions occupy the tetrahedral site while $\mathrm{O}_{11}^{2-}$ occupy the octahedral site. Oxygen ions in tetrahedral site form a covalent bond with lanthanum, which can be written $[\mathrm{LaO}]^{1+}$. Considering the chemical and crystallographic properties of $\mathrm{Tl}$ and $\mathrm{Bi}$ compounds, $[\mathrm{TlO}]^{1+}$ and $[\mathrm{BiO}]^{1+}$ groups appear as defined by strong covalent bonds between $\mathrm{Bi}$ or $\mathrm{Tl}$ and $\mathrm{O}$. This leads to the supposition that the four oxygen ions which coordinate to copper in $\mathrm{Tl}$ and $\mathrm{Bi}$ copper oxide-based superconductors are $\mathrm{O}_{11}^{1-}$ ions. The bivalent character of copper is then obtained through covalent bonds. For $\mathrm{La}_{2}{ }_{-x} \mathrm{Sr}_{x} \mathrm{O}_{4}$ compounds, copper is supposed to have valence three, but spectroscopic studies point out bivalent copper. We show that krypton shell of $\mathrm{Sr}$ is responsible for the lack of one unit of valence as expected from krypton compounds for example $\mathrm{KrF}_{2}$.
\end{abstract}

Keywords. Valence and bond; oxygen $2 p$ holes; copper valence; $\mathrm{Sr}-\mathrm{Kr}$ shell valence; $\mathrm{Ba}-\mathrm{Xe}$ shell valence.

\section{Introduction}

The exact valence state of copper in copper-based new high- $T_{c}$ materials has been the subject of controversy as indicated by several reports. The trivalent copper appears to play an insignificant role in the mechanism of superconductivity and of late it has been realized that there is perhaps no such ion! Although spectroscopic results indicate the existence of $\mathrm{O}(2 p)$ holes in different $\mathrm{Cu}$-based superconductors, yet there is no striking evidence for $\mathrm{Cu}_{111}$ In this work, an attempt has been made to explain such intriguing results.

We first recall difference between valence (also oxidation number abbreviated as o.n) and ionicity brought out in the previous work by Oudet (1983). Then we present a general concept of a covalent bond with a hole on the oxygen on the one hand and a covalent electron belonging to its cation on the other. We propose that copper with valence two in such compounds can keep all its valence electrons. To understand the absence of characteristic spectral properties of $\mathrm{Cu}_{\text {III }}$ where they are expected, we propose a xenon-barium shell or krypton-strontium shell contribution as a consequence of the existence of rare gas compounds.

In the light of these new ideas on bonding characteristics of copper barium and strontium, it has been possible to understand different crystallographic and valence properties of these compounds. A valence competition between $\mathrm{Cu}_{\mathrm{II}}$ and $\mathrm{Ba}-\mathrm{Xe}$ or $\mathrm{Sr}-\mathrm{Kr}$ shell might be a possible reason for the observed electrical conductivity behaviour of these compounds in their normal state. 


\section{Oxygen holes and covalent bonds}

To bring out the distinction between the ionicity and valence, we first consider the sesquioxide of lathanum, $\mathrm{La}_{2} \mathrm{O}_{3}$ which crystallizes with hexagonal close-packing of lanthanum cations. In this packing for two lanthanum, there are two oxygen ions in a tetrahedral site another in octahedral site. To explain these two sites for oxygen, we suppose that La has just two ionic bonds from its $6 s^{2}$ electrons and the third electron responsible for $0 . n$. three is deep and retained by cation, so $\mathrm{La}_{2} \mathrm{O}_{3}$ is described as:

$$
\mathrm{La}_{2} \mathrm{O}_{3} \rightarrow \mathrm{O}^{2-}+2 \mathrm{O}^{1-}+2 \mathrm{La}^{2+} .
$$

The octahedral site corresponds to $\mathrm{O}^{2-}$ and tetrahedral site to two $\mathrm{O}^{1-}$. The valence II for $\mathrm{O}^{1-}$ and III for $\mathrm{La}^{2+}$ is arrived at through a covalent bond with the third electron of La. To bring out the difference between the ionicity and the valence, we denote the corresponding ions $\mathrm{La}_{\text {III }}^{2+}$ and $\mathrm{O}_{11}^{1-}$ also denote $\mathrm{La}(2+, \mathrm{III})$ and $\mathrm{O}(1-, \mathrm{II})$ or in brief $[\mathrm{LaO}]^{+}$. However this representation should not be mistaken for the existence of a molecular group in the crystal. Further we suppose that each $\mathrm{La}^{2+}$ contributes to the lack of one electron to as many neighbouring $\mathrm{O}_{11}^{1-}$ as possible. The fact that the two oxygen sites exhibit differences in chemical and physical properties supports our hypothesis. This distinction between ionicity and valence is easy to generalize to rare earths because their oxysulphides crystallize with the $\mathrm{La}_{2} \mathrm{O}_{3}$ structure in which sulphur is in octahedral site.

The same hypothesis is invoked for $3 d$ cations considering ferrites $\mathrm{RFe}_{2} \mathrm{O}_{4}(\mathrm{R}=3 d$ cation) with spinel structure. Let us consider $\mathrm{Fe}_{3} \mathrm{O}_{4}$, according to the classical understanding, both $\mathrm{Fe}^{2+}$ and $\mathrm{Fe}^{3+}$ should be located in octahedral site, thus leading to a charge ordering at low temperature. A great deal of work has been done to establish it by Samuelsen et al (1968); Fuji et al (1975); Yoshiba et al (1977) but without success. This leads to the supposition that $3 d$ cations have ionicity $2^{+}$and o.n. higher than two. Consequently the problem of charge ordering disappears and several results concerning $\mathrm{Fe}_{3} \mathrm{O}_{4}$ are better understood. It is gratifying to note that from different considerations in the field of low-energy-ions and fast neutron bombardments, the hypothesis of $\mathrm{O}^{1-}$ ions together with $\mathrm{Fe}^{2+}$ instead of $\mathrm{O}^{2-}$ and $\mathrm{Fe}^{3+}$ ions have recently been proposed by Pascard $(1984,1986)$.

Let us now describe the covalent bond between the $\mathrm{M}_{\mathrm{II}}^{2+}$ cations and $\mathrm{O}_{\mathrm{II}}^{1-}$ oxygen ions. The covalent bond is the result of an attraction between the third deep valence electron of the cation and the nucleus of the anions which are not well screened because of an unoccupied $2 p$ state. In this view the third valence electron of the cation (giving the covalent bond) is more or less attracted by the $\mathrm{O}_{\mathrm{II}}^{1-}$ ions but from our point of view it shall belong to the cation.

We note here that the attraction of a valence electron resulting from an unoccupied quantum state on the anion is another way of expressing the valence three. The problem now is to understand the existence of $\mathrm{O}(2 p)$ hole with $\mathrm{Cu}_{11}$ as found in $\mathrm{Tl}_{2} \mathrm{Ba}_{2} \mathrm{CaCu}_{2} \mathrm{O}_{8}$.

\section{Thallium and bismuth compounds}

Both $\mathrm{Tl}$ and $\mathrm{Bi}$ have valence three and $\mathrm{Tl}$ is also known to have valence one. Since the chemical properties of $\mathrm{Tl}_{\mathrm{I}}$ are close to those of alkali metals that are typically 
ionic and for this reason we suppose the existence of $\mathrm{Tl}_{111}^{1+}$ and with oxygen bond as $[\mathrm{TlO}]^{1+}$. This species is similar to the chemical species $[\mathrm{VO}]^{2+}$ and $[\mathrm{TiO}]^{2+}$ as in $\mathrm{SO}_{4}(\mathrm{VO})$ and $\mathrm{SO}_{4}(\mathrm{TiO})$. In all these chemical species we must consider two covalent bonds between the cation and the oxygen as in the approach to iron with valence two and three giving $\mathrm{Fe}_{\text {III }}^{2+}$ ion.

Let us now consider bismuth. Bismuthyl chloride $\mathrm{Cl}(\mathrm{BiO})$ is known. It crystallizes with the $(\mathrm{PbF}) \mathrm{Cl}$ structure as $(\mathrm{LaO}) \mathrm{Cl}$. For $\mathrm{BiO}$ and $\mathrm{LaO}$, the distances are shorter than the sum of the ionic radii; for $\mathrm{BiCl}$ and $\mathrm{LaCl}$ it is the opposite. There is an indication of the covalent character of the bonds between $\mathrm{Bi}$ and $\mathrm{O}$ or $\mathrm{La}$ and $\mathrm{O}$, while there is a strong ionic character of the bond between $\mathrm{Bi}$ and $\mathrm{Cl}$ and $\mathrm{La}$ and $\mathrm{Cl}$. This clearly suggests a molecular description as $[\mathrm{BiO}]^{+}$and $\mathrm{Cl}^{-}$or $[\mathrm{LaO}]^{+}$and $\mathrm{Cl}^{-}$. Further comparison between $\mathrm{La}_{2} \mathrm{O}_{2} \mathrm{~S}$ and $\mathrm{LaOCl}$ confirms this description. Thus we have a strong indication of the existence of the bismuthyl group $[\mathrm{BiO}]^{+}$. With such $[\mathrm{BiO}]^{+}$and $[\mathrm{TlO}]^{+}$groups, we can now try to describe the electronic state of copper in the new high- $T_{r}$ superconductors.

\section{Copper valence bonds}

To describe the electronic state of copper let us first consider $\mathrm{Tl}_{2} \mathrm{Ba}_{2} \mathrm{CaCu}_{2} \mathrm{O}_{8}$. According to its crystal structure, this compound can be described as a stacking of layers having the following composition:

$$
\mathrm{TlO} / \mathrm{BaO} / \mathrm{CuO}_{2} / \mathrm{Ca} / \mathrm{CuO}_{2} / \mathrm{BaO} / \mathrm{TlO} \text {. }
$$

According to the hypothesis of $[\mathrm{TlO}]^{1+}$ group, the ionic character of $\mathrm{Ca}_{11}$ giving $\mathrm{Ca}^{2+}$ and the fact that each barium atom balances the valence of one oxygen atom, for one formula $\mathrm{Tl}_{2} \mathrm{Ba}_{2} \mathrm{CaCu}_{2} \mathrm{O}_{8}$, we can consider the following groups and electronic exchanges:

$$
2[\mathrm{TlO}]^{1+}+2 \mathrm{BaO}+\mathrm{Ca}^{2+}+2\left[\mathrm{Cu}, 2 \mathrm{O}^{1-}\right] .
$$

As a result, in each $\mathrm{CuO}_{2}$ plane each oxygen atom gets one additional electron. Therefore, in the $\mathrm{CuO}_{2}$ planes we actually have $\mathrm{Cu}$ and $2 \mathrm{O}(1-, 11)$. As already evidenced from different spectroscopic experiments, the presence of $\mathrm{O}(2 p)$ holes has been established in different copper oxides: $\mathrm{YB}_{2} \mathrm{Cu}_{3} \mathrm{O}_{7}, \mathrm{La}_{2-x} \mathrm{Sr}_{x} \mathrm{CuO}_{4}, \mathrm{Bi}_{2} \mathrm{Sr}_{2} \mathrm{CaCu}_{2} \mathrm{O}_{8}$ as reported by Himpsel et al (1988); Nucker et al (1989), and $\mathrm{Tl}_{2} \mathrm{Ba}_{2} \mathrm{CaCu}_{2} \mathrm{O}_{8}$ by Meyer et al (1989). We suppose that the spectral lines leading to the existence of these holes mainly have the same origin. The singular feature in the crystal structure of these compounds is the presence of $\mathrm{CuO}_{2}$ planes. Thus it seems that the holes must be associated with the oxygen atoms of these planes. In addition strong indication of such $\mathrm{O}(2 p)$ holes have also been found in pure $\mathrm{CuO}$ by Grioni (1989). Thus we suppose that copper with valence two in such compounds and perhaps in many if not for all, keeps all its electrons. The valence electrons give strong covalent bonds leading to the coordination properties. Thus the $\mathrm{Cu}(\mathrm{O}, \mathrm{II})$ atom coordinates with four $\mathrm{O}(1-, \mathrm{II})$ ions and it is clear that each covalent electron from copper contributes to a covalent bond with more than one $\mathrm{O}(1-, \mathrm{II})$ ion. On the other hand each $\mathrm{O}(1-, \mathrm{II})$ ion receives a covalent contribution from its two copper neighbours.

According to the hypothesis of $\mathrm{O}(1-, \mathrm{II})$, there must be a signature of such ions not only with the copper oxides but also with $\mathrm{La}_{2} \mathrm{O}_{3}$ or even with $\mathrm{La}_{2} \mathrm{CuO}_{4}$ where 
$O(2 p)$ holes have not yet been suspected. The problem is that according to the classical scheme of ionicity with $\mathrm{O}^{2-}$ ions, we have to understand the experimental results without recourse to $2 p$ holes. The actual possibility of $\mathrm{O}(2 p)$ holes emerges from the low-energy value observed for the oxygen $1 s \rightarrow 2 p$ transition according to the doping in $\mathrm{La}_{2-x} \mathrm{Sr}_{x} \mathrm{CuO}_{4}$, and with $\mathrm{YBa}_{2} \mathrm{Cu}_{3} \mathrm{O}_{7-\delta}$ according to $\delta$ and then with the $\mathrm{Bi}$ or $\mathrm{Tl}$ copper oxides. Now we must find an explanation for the existence of these oxygen $2 p$ holes. This work aims to find an explanation, according to which we are able to understand different crystallographic properties and related chemical properties, as weil as some magnetic properties. In the light of this, we have to reconsider the explanation of some results in spectroscopy. We are confident that $\mathrm{O}(2 p)$ holes associated with lanthanum or other cations as those of $\mathrm{Bi}_{\mathrm{III}}$ or $\mathrm{Tl}_{\mathrm{III}}$ will be recognized; the hypothesis of such holes have been proposed long before their discovery with the copper oxide compounds by Oudet (1983). Now all the other copper-based new high- $T_{c}$ superconductors have at least one $\mathrm{CuO}_{2}$ plane. It is easy to see that they can also be described as $\mathrm{Cu}, 20(1-$, II $)$ and that the hypothesis of $\mathrm{Cu}(0$, II $)$ still holds.

\section{Ba-Xe or $\mathrm{Sr}-\mathrm{Kr}$ shell contribution to the valence}

In the compound $\mathrm{La}_{2} \mathrm{CuO}_{4}$ the stacking sequences are the following:

$$
\text { ... } \mathrm{LaO} / \mathrm{CuO}_{2} / \mathrm{LaO} \ldots
$$

According to the hypothesis of $\mathrm{La}(2+, \mathrm{III})$ ions or $[\mathrm{LaO}]^{1+}$ groups we get the same description of the $\mathrm{CuO}_{2}$ planes as in other compounds already discussed. Lanthanum gives two electrons for ionic bonds and we can write:

$$
2[\mathrm{LaO}]^{1+}+\left[\mathrm{CuO}_{2}\right]^{2-}
$$

In comparison to $\mathrm{Tl}_{2} \mathrm{Ba}_{2} \mathrm{CuO}_{6}$ we have in both compounds one $\mathrm{CuO}_{2}$ plane sandwiched between two $\mathrm{MO}$ planes, $\mathrm{BaO}$ for the thallium compound and $\mathrm{LaO}$ for $\mathrm{La}_{2} \mathrm{CuO}_{4} \cdot \mathrm{Tl}_{2} \mathrm{Ba}_{2} \mathrm{CuO}_{6}$ is a superconductor with $T_{c}=80 \mathrm{~K}$, while $\mathrm{La}_{2} \mathrm{CuO}_{4}$ is not. Furthermore when $\mathrm{La}$ is replaced by $\mathrm{Sr}$ or $\mathrm{Ba}$ it becomes a superconductor for an appropriate ratio. This clearly suggests that the superconducting property is related to the stacking of $\mathrm{MO} / \mathrm{CuO}_{2} / \mathrm{MO}$ with $\mathrm{M}$ for $\mathrm{Sr}$ or $\mathrm{Ba}$. When we replace $\mathrm{La}$ by $\mathrm{Sr}$ or $\mathrm{Ba}$, we replace in the present description $\mathrm{La}(2+, \mathrm{III})$ by $\mathrm{Sr}(2+, \mathrm{II})$ or $\mathrm{Ba}(2+, \mathrm{II})$. As a result there is one missing valence electron to balance the oxygen valence.

When superconductivity in these compounds was discovered, it was thought that the copper with the valence three makes the balance for the oxygen valences. Indeed several compounds with $\mathrm{Cu}_{\text {III }}$ are known; for example, $\mathrm{LaCuO}_{3}, \mathrm{NaCuO}_{2}$ and $\mathrm{LaSrCuO}_{4}$. The studies of Michel and Raveau (1984) on the mixed copper oxides related to the perovskite where $\mathrm{Cu}_{\mathrm{III}}$ is supposed to have an important structural role have been used in the research which led Bednorz and Muller to their discovery.

From atomic absorption spectroscopy the presence of $\mathrm{Cu}_{111}$ is characterized by a shift toward high energy of some structures when compared to that of $\mathrm{Cu}_{11}$ : for example the main line $2 p_{3 / 2}$ in XPS of $\mathrm{NaCuO}_{3}$ compared to that of $\mathrm{CuO}$ as observed by Ospelt et al (1988). Similar observations have been made with other $\mathrm{Cu}_{\mathrm{III}}$ compounds by Bianconi et al (1987); Dauth et al (1987); Tranquda et al (1987); Alp et al (1987). But the characteristic structure of $\mathrm{Cu}_{m i}$ does not appear so well in $\mathrm{La}_{2-x} \mathrm{Sr}_{x} \mathrm{O}_{4}$ or $\mathrm{YBa}_{2} \mathrm{Cu}_{3} \mathrm{O}_{7}$. It can even appear that there is no $\mathrm{Cu}_{111}$ at all. With 
the discovery of the $\mathrm{Bi}$ and $\mathrm{Tl}$ superconductors, $\mathrm{Cu}_{\mathrm{III}}$ was still thought to be responsible for superconductivity. In our opinion the stoichiometry of the thallium compounds as $\mathrm{Tl}_{2} \mathrm{Ba}_{2} \mathrm{CaCu}_{2} \mathrm{O}_{8}$ is an indication that superconductivity can be observed with just $\mathrm{Cu}_{\mathrm{II}}$. But whatever the precise valence state of copper that we can expect, in $\mathrm{Bi}$ and Tl compounds from spectroscopic studies by Nucker et al (1989); Meyer et al (1989), evidence of $\mathrm{Cu}_{111}$ has not been found. For any model we have to understand these experimental results. These puzzling results strongly suggest that in understanding the valence we have to find something which has never been suspected up to now.

Let us consider the discovery of rare gas compounds by Chernick et al (1962). According to the classical understanding of the valence, the rare gases have been supposed to be chemically inactive. As they are not, there is no reason why the corresponding inner shells should be chemically inactive as supposed up to now. For example the Xe shell of Ba can be supposed to have some contribution to the balance of valence. Such a possibility has already been invoked to elucidate the cerium problem by Oudet $(1987,1989)$. In such an eventuality, the very similar XPS or EELS spectra to assign the valence state of $\mathrm{Cu}$ in $\mathrm{La}_{2-x} \mathrm{Sr}_{x} \mathrm{CuO}_{4}(x=0$ or $x \neq 0)$ and in $\mathrm{YBa}_{2} \mathrm{Cu}_{3} \mathrm{O}_{7-\delta}(\mathrm{O} \leqslant \delta \leqslant 1)$ will be just a natural consequence of copper as $\mathrm{Cu}_{\mathrm{II}}$. Similar arguments can be put forth for $\mathrm{Sr}$ according to the krypton shell since there are also krypton compounds.

\section{Conclusions}

In conclusion, let us consider oxygen with $2 p$ holes in the $\mathrm{CuO}_{2}$ planes. As a result of the Coulomb attraction, such oxygen ions must attract as much as possible with similar covalent electrons such as those of its two neighbouring copper atoms. But such an attraction can also take place with other cations than $\mathrm{Cu}$. We suppose that the xenon shell of Ba or the krypton shell of Sr can also contribute to the lack of one electron on the oxygen, even if according to the classical approach of the valence there is a balance of the valence between cations and anions. This is certainly what happens in compounds like $\mathrm{Tm}_{2} \mathrm{Ba}_{2} \mathrm{CaCu}_{2} \mathrm{O}_{8}$ or $\mathrm{Bi}_{2} \mathrm{Sr}_{2} \mathrm{CaCu}_{2} \mathrm{O}_{8}$ where copper has the valence two and where in the classical approach of the valence there is no difficulty to decide on the valence state of each element.

We arrive at the following situation in the $\mathrm{CuO}_{2}$ plane: there are $\mathrm{O}(1-$, II $)$ ions with bonds from the $\mathrm{Cu}(0, \mathrm{II})$ atom. But the $\mathrm{O}(1-, \mathrm{II})$ ions also receive a contribution due to the lack of one electron from the xenon shell of the neighbouring $\mathrm{Ba}^{2+}$ ions or from the krypton shell of their neighbouring $\mathrm{Sr}^{2+}$ ions. Thus there are competing bonds with $\mathrm{O}(1-, \mathrm{II})$ : one from $\mathrm{Cu}$ and another one from $\mathrm{Ba}^{2+}$ or $\mathrm{Sr}^{2+}$. The contribution from $\mathrm{Ba}-\mathrm{Xe}$ or $\mathrm{Sr}-\mathrm{Kr}$ shell makes the covalent bond between $\mathrm{Cu}$ and $\mathrm{O}(1-$, II $)$ less stronger than without such a contribution. It seems reasonable to suppose that the electrical properties of these compounds are closely linked with these bond properties.

\section{References}

Alp E E 1987 Phys. Ret. B35 7199

Bianconi A et al 1987 Solid State Commun. 631135 
Chernick C L et al 1962 Science 2, 138136

Dauth B et al 1987 Z. Phys. B68 407

Fujii Y et al 1975 Phys. Rev. B11 2036

Grioni M 1989 Phys. Rev. B39 4886

Himpsel F J et al 1988 Phys. Rev. B38 11946

Meyer H M et al 1989 Phys. Rev. B39 7343

Michel C and Raveau B 1984 Rev. Chim. Min. 21407

Nucker N et al 1989 Phys. Rev. B39 6619

Ospelt M et al 1988 Physica C153-155 159

Oudet X 1983 Ann. Chim. Fr. 8483

Oudet X 1987 Theoretical and experimental aspects of valence fluctuations and heavy fermions-Proceedings of 5ih International Conference on Valence Fluctuations (7-9 January 1987) (Bangalore: Plenum Publ. Corp.)

Oudet X 1989 Czech. Chem. Commun. 54551

Pascard H 1984 Phys. Rev. B30 2299

Pascard H 1986 Phys. Rev. B33 7552

Samuelson E J et al 1968 J. Appl. Phys. 391114

Tranquada J M et al 1987 Phys. Rev. B35 7187

Yashida J and lida S 1977 J. Phys. Soc. Jpn. 42230 